\title{
Numerical Simulation of the Effects on Low Temperature Drainage from LNG on the Ocean Water Environment
}

\author{
Mingyuan Sun'1,2, Yi Zhang2,3, Longxi Han',3, Bo Chen ${ }^{2,3}$, Tiantian Liu1 \\ ${ }^{1}$ College of Environment, Hohai University, Nanjing, China \\ ${ }^{2}$ Ocean and Fisheries Bureau of Jiangsu Province, Nanjing, China \\ ${ }^{3}$ Key Laboratory of Integrated Regulation and Resource Development on Shallow Lake of Ministry of Education, College of \\ Environment, Hohai University, Nanjing, China \\ Email: hhuzhangyi@live.com
}

How to cite this paper: Sun, M.Y., Zhang, Y., Han, L.X., Chen, B. and Liu, T.T. (2017) Numerical Simulation of the Effects on Low Temperature Drainage from LNG on the Ocean Water Environment. World Journal of Engineering and Technology, 5, 71-80.

https://doi.org/10.4236/wjet.2017.53B009

Received: July 4, 2017

Accepted: August 8, 2017

Published: August 11, 2017

\begin{abstract}
In order to research the distribution of thermal field of low temperature discharge from LNG in the ocean, further to formulate reasonable wastewater marine disposal scheme and provide scientific support to the protection of ocean environment, a two-dimensional hydrodynamic model was used to simulate the tide current field in the radial sand ridge group of shallow sea area of Jiangsu maritime space. This model was based on the tide current characteristics near the LNG project and the seasonal design of the typical hydrological conditions in different seasons. This model was used as the hydrodynamic condition that simulated the transport and diffusion for the heat quantity in the change of time and spatial distribution. Considering the comprehensive heat radiation coefficient of water surface, the 2-D water temperature model was established to predict the spatial distribution and temporal variation of the temperature field in the receiving waters. Finally, results showed that the low temperature drainage less affected in the ocean water environment.
\end{abstract}

\section{Keywords}

LNG, Immediate Offshore Area, 2-D Numerical Model, Water Temperature

\section{Introduction}

Ocean is an important part of the global life support system and also a natural resource for human survival. Its huge water and good hydrodynamic conditions has become an ideal place for acceptance and purification of tail water. Coastal 
waters, as the most closely related to human activities in the ocean, are deeply affected by human activities. In recent years, as the world energy crisis intensifies, vigorously develop Liquefied Natural Gas (LNG) project in the coastal areas is becoming an important part of China's energy strategy. However, in the process of the production, the sea water is changed into the ocean after heat transfer as the heating medium, and has a certain degree of influence on the water environment in the coastal area [1]. Therefore, it is very important to study the hydrodynamic characteristics of the coastal waters and the 2-D temperature distribution model of the relevant sea areas. It will make a reasonable planning of marine resources protection for the environmental protection departments and provide strong scientific support for marine engineering decision.

Yaohua Dong established a 2-D water flow, temperature and concentration transport numerical model of river, processed the determination of parameters and coefficient, selection of boundary definite condition, the treatment of shore boundary and moving boundary, and proved the feasibility and applicability of the model [2]. The finite nodal method was based on the triangular grid and the sliding boundary condition was used to deal with the change of water level by Bin Luo [3]. Zhenhai Li from China Institute of Water Resources and Hydropower Research used the windward format to deal with the convective term of the momentum equation, used the central difference scheme to deal with the diffusion term, used the control volume method to deal with the continuity equation and heat transfer equation. Then, the flow field and temperature field of discharge from power plant are solved [4]. Haijie $\mathrm{Wu}$ predicted for the heated discharge from coastal power plant. He used dry wet unit hydraulic model to deal with the calculation of complicated boundaries, established a second-order Osher format water-temperature model, which provided a reliable technical data for marine environmental impact assessment [5]. But the study above has not forecast the maximum possible influence range of temperature.

In this paper, a low temperature drainage problem from the LNG project was used as a research example, and hydrological conditions of summer is generally larger than that of winter. The tide current field in shallow sea area of Jiangsu coastal area was simulated through 2-D hydrodynamic model, and the time variation and spatial distribution characteristics of pollutant migration and transformation in the receiving sea area were simulated based on these hydrodynamic conditions. The heat of the 2-D convection diffusion model was established, and which was used to forecast the temperature field of temporal and spatial distribution characteristics considering the premise of water heat transfer effect. In the forecast, maximum influence range of the low temperature drainage was the focus, which meant that the value of the temperature envelope line selected the maximum value of the whole simulated period at one point in the position, so as to provide the basis for the maximum ecological environment security of the adjacent water area of the LNG project. 


\section{Hydrodynamic Simulation}

A 2-D hydrodynamic model was used to simulate the tide current field in the shallow sea area of the radial sand ridges in the Jiangsu coast (see Figure 1). The range from south to north is $31^{\circ} 58^{\prime} \mathrm{N}-33^{\circ} 14^{\prime} \mathrm{N}$, the spacing is $152 \mathrm{~km}$; the range from east to west is $120^{\circ} 46^{\prime} \mathrm{E}-121^{\circ} 51^{\prime} \mathrm{E}$, width across $102 \mathrm{~km}$, and the total area of the calculation area is about $9850 \mathrm{~km}^{2}$.

Different combination of sequence boundary points on the tide level process was taken as the input condition of hydrology. Due to the location of the tide stations in the area was not conducive to the model boundary conditions in the study area, the tide data couldn't be used as a tide of input data to simulate the moving boundary. Therefore, the ocean tide assimilation model (TPXO) was used to obtain the boundary of tide level process, which is one of the 7 ocean tide models in the world. In order to verify the accuracy of the model, we simulated the hydrodynamic conditions during April 24, 2008 to May 6, 2008, in which period contained more measured data. This method is mature, many literatures have discussed, so it would not repeat in this article [6] [7].

\subsection{Hydrodynamic Model Validation}

According to the measured data report of the relevant ocean hydrological observation, took the tide observation data to validate the hydrodynamic model, and compared the consistency between the calculation of tide level and tide duration and the measured value. The longitude and latitude of the tide observation stations are shown in Table 1. CW1-CW4 tide stations results shown in Figures 2-4.

Visible from above, the simulation results of tide level and tide duration are in good agreement with observation data. Based on the tide level and tide duration

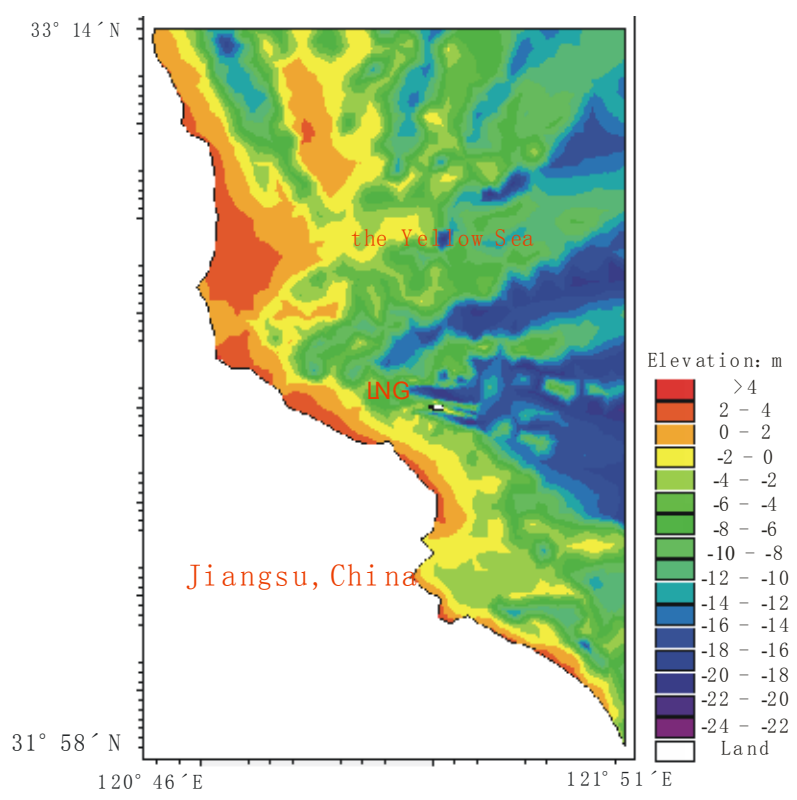

Figure 1. Sea area terrain around LNG project. 


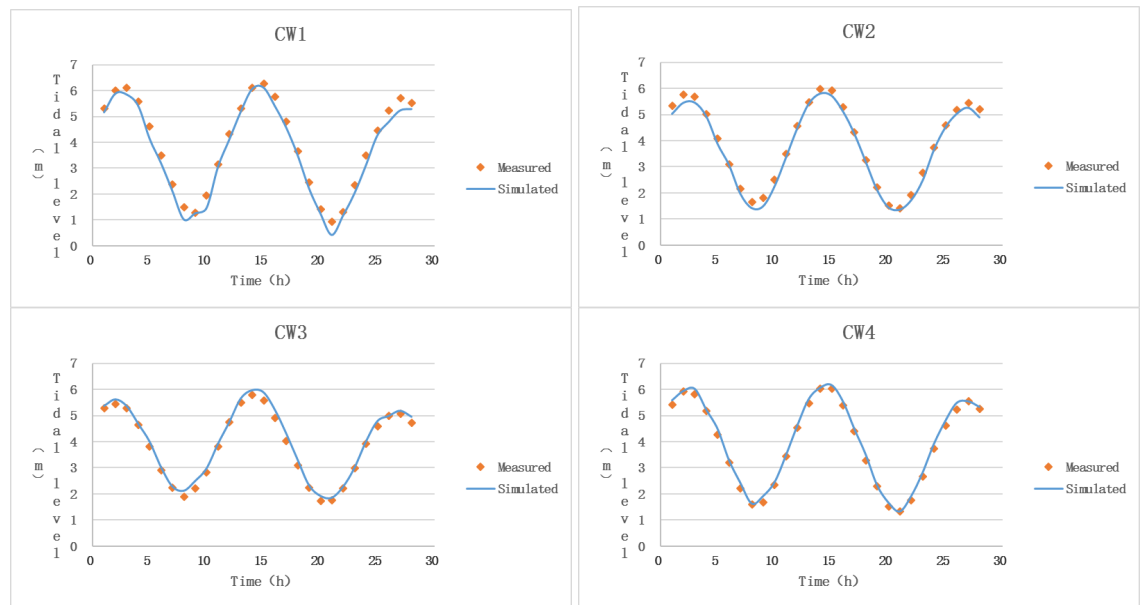

Figure 2. Verification process of the mid tide on April 2008 24-25.

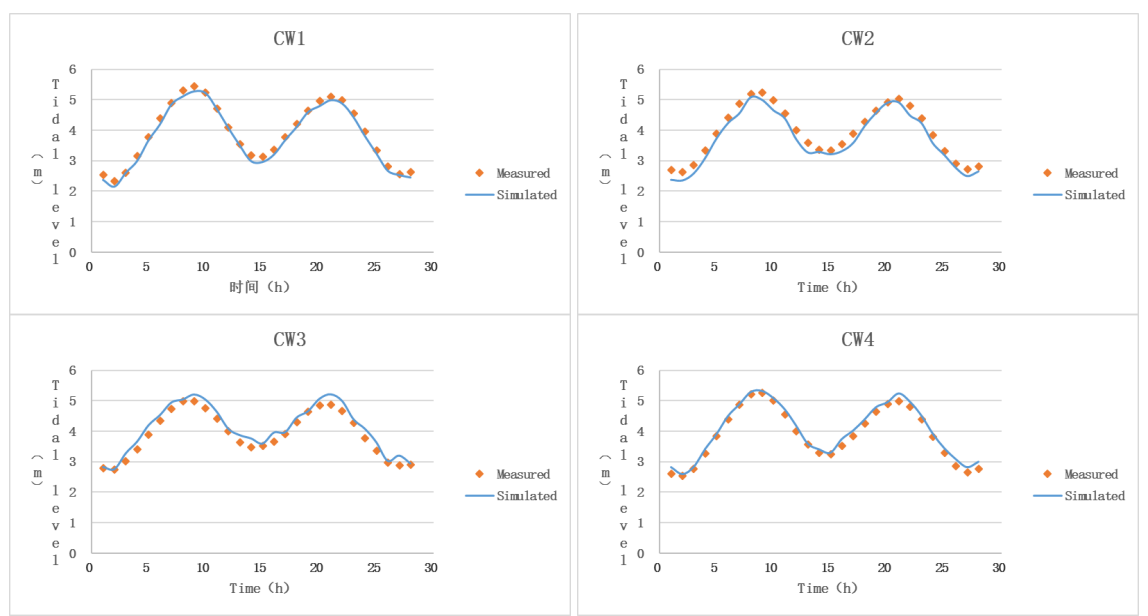

Figure 3. Verification process of the neap tide on April 2008 28-29

Table 1. The longitude and latitude of the tide observation stations.

\begin{tabular}{ccc}
\hline \multirow{2}{*}{ Tide Stations } & \multicolumn{2}{c}{ Location } \\
\cline { 2 - 3 } & Longitude & Latitude \\
\hline CW1 & $121^{\circ} 09^{\prime} 20^{\prime \prime} \mathrm{E}$ & $32^{\circ} 34^{\prime} 39^{\prime \prime} \mathrm{N}$ \\
CW2 & $121^{\circ} 24^{\prime} 05^{\prime \prime} \mathrm{E}$ & $32^{\circ} 30^{\prime} 27^{\prime \prime} \mathrm{N}$ \\
$\mathrm{CW} 3$ & $121^{\circ} 38^{\prime} 46^{\prime \prime} \mathrm{E}$ & $32^{\circ} 27^{\prime} 36^{\prime \prime} \mathrm{N}$ \\
$\mathrm{CW} 4$ & $121^{\circ} 21^{\prime} 25^{\prime \prime} \mathrm{E}$ & $32^{\circ} 34^{\prime} 58^{\prime \prime} \mathrm{N}$ \\
\hline
\end{tabular}

verification above, it shows that the model could reflect the current situation of the hydrodynamic conditions well. Therefore, the grid layout, boundary conditions and calculation parameters could be used to simulate the hydrodynamic conditions in the predicted area well.

\subsection{Hydrodynamic simulation results}

Considering the seasonal difference of tidal current in the predicted area, the 
different flow field directly affects the migration and diffusion of pollutants, so as to influence the prediction results. Select summer and winter two seasons as a typical period of time to simulate the hydrodynamic conditions in the region. Flow field distribution of summer and winter are shown in Figure 5 and Figure 6.

\subsection{Hydrodynamic Characteristics Analysis}

The results show that, the main trend of the flow was similar to NE-SW during the flood tide, which is perpendicular to the coastline, and when the ebb tide is opposite. The regional flow rate is generally larger, the flow rate of the summer

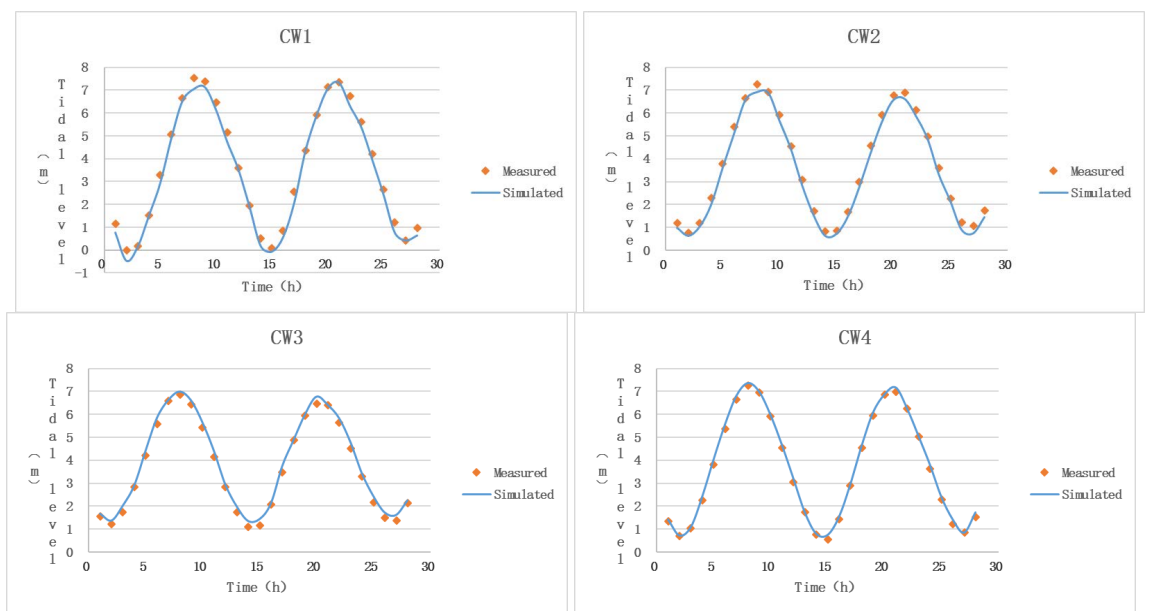

Figure 4. Verification process of the spring tide on May 2008 5-6.
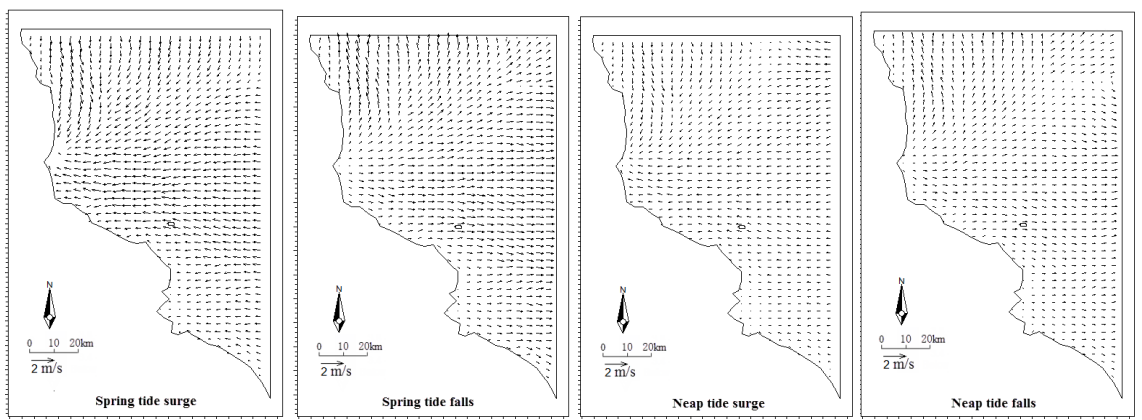

Figure 5. Summer flow field map.
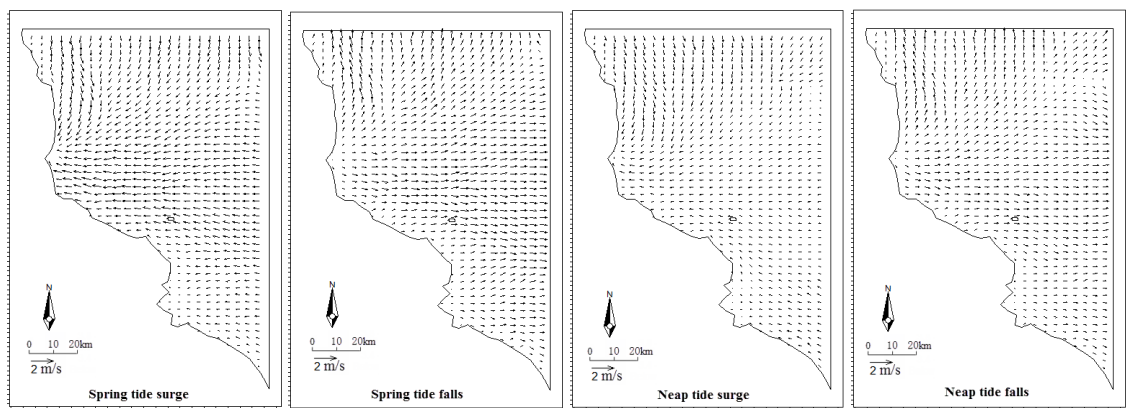

Figure 6. Winter flow field map. 
was significantly greater than that in winter, and the water velocity of the flood tide is higher than the ebb tide.

In the area near the shore, affected by the shoreline and topography, tidal current flows paralleled to the shore, and the local water flow is different from the main tidal current due to the change of coastline. Overall, during the flood tide, the trend in the northern coast area is southward, the trend in southern coast area is in the direction of the northeast, and when the ebb tide it is opposite. The velocity of water flow in the near shore water is less than the velocity of the water.

The drainage outlet is located on the artificial island which has a certain distance from the shore boundary, so the velocity and direction is less affected by the shore, and the water flow condition is relatively simple. Results shows that, the flow direction is approximately west at the sewage outfall during the flood tide, and the flow direction is east during the ebb tide. The average velocity at the outfall was $0.253 \mathrm{~m} / \mathrm{s}$ in spring tide and $0.182 \mathrm{~m} / \mathrm{s}$ in neap tide.

\section{Chlorine and Water Temperature Distribution Simulation}

\subsection{2-D Heat Diffusion Equation}

$$
\frac{\partial T}{\partial t}+u \frac{\partial T}{\partial x}+v \frac{\partial T}{\partial y}=\frac{\partial}{\partial x}\left(K_{x} \frac{\partial T}{\partial x}\right)+\frac{\partial}{\partial y}\left(K_{y} \frac{\partial T}{\partial y}\right)+\hat{H}+T_{S} S
$$

Form in: $T$-- receiving water temperature, ${ }^{\circ} \mathrm{C}$; $t$ - - time, $\mathrm{s} ; u, v--$ vertical and horizontal vertical average velocity, $\mathrm{m} / \mathrm{s} ; K_{x}, K_{y}$ - - thermal diffusion coefficient of water body, $\mathrm{m}^{2} / \mathrm{s} ; \hat{H}$ - source terms of water gas heat exchange; $T_{\mathrm{s}}$-source term temperature, ${ }^{\circ} \mathrm{C} ; S$-source term flow, $\mathrm{m}^{3} / \mathrm{s}$.

\subsection{Definite Solution Condition}

Boundary condition

Shore boundary

$$
\frac{\partial \theta}{\partial n}=0
$$

Form in: $\bar{n}$ is boundary normal.

Open boundary

Low tide:

$$
\frac{\partial \theta}{\partial t}+\bar{u} \bullet \frac{\partial \theta}{n} \frac{\partial \theta}{\partial n}=0
$$

High tide:

$$
\theta=0
$$

All initial conditions are 0.

\subsection{Determination of Parameters and Source Strength}

\subsubsection{Diffusion Coefficient}

The velocity field in natural sea area is generally not uniform. Diffusion coeffi- 
cient is an important parameter which is not easy to be determined, and it often has the property of empirical coefficient. The diffusion coefficient formula used in this paper was as follows:

$$
\begin{gathered}
E_{x}=\alpha_{x} h u_{*} \\
E_{y}=\alpha_{y} h u_{*}
\end{gathered}
$$

Form in: $h-$-water depth, $\mathrm{m} ; u_{*}$ - frictional velocity $\left(u_{*}=\sqrt{g h j}, j\right.$ is hydralic gradient), $\mathrm{m} / \mathrm{s} ; \alpha_{x}, \alpha_{y}-$ - empirical coefficient, respectively taken as 4.0 and 0.5.

\subsubsection{Water Surface Integrated Heat Dissipation Coefficient}

The water surface comprehensive heat dissipation coefficient Ks was calculated by Gunnerberg formula of foreign experience formula, and the influence of wind and sea water temperature on thermal diffusion was considered:

$$
\begin{aligned}
K_{s}= & 2.2 \times 10^{-7} \times(t+273.5)^{3}+0.0015 \\
& \times\left[\frac{(2501.7-2.366 \times t) \times 25509.0 \times 10^{\frac{7.56 \times t}{t+239.7}}}{(t+239.7)^{2}}+1621\right]
\end{aligned}
$$

Form in: $t$ - -water surface temperature.

\subsubsection{Pollutant Source Concentration}

According to the data, the original concentration of the drainage of a LNG receiving station project was $10.35 \mathrm{~m}^{3} / \mathrm{s}$ during operation, the water temperature was 3 degrees lower than the normal water.

\subsection{Forecast Result}

In this paper, we used the above model and its solution, simulated the full tide cycle under two typical hydrological conditions in winter and summer by considering the most adverse effects, and predicted the temperature increment and range. The equivalent envelope line of the water temperature drop value near the drains in winter and summer are shown in Figure 7 and Figure 8, and the spatial distribution statistical parameters of contour lines are shown in Table 2 and Table 3.

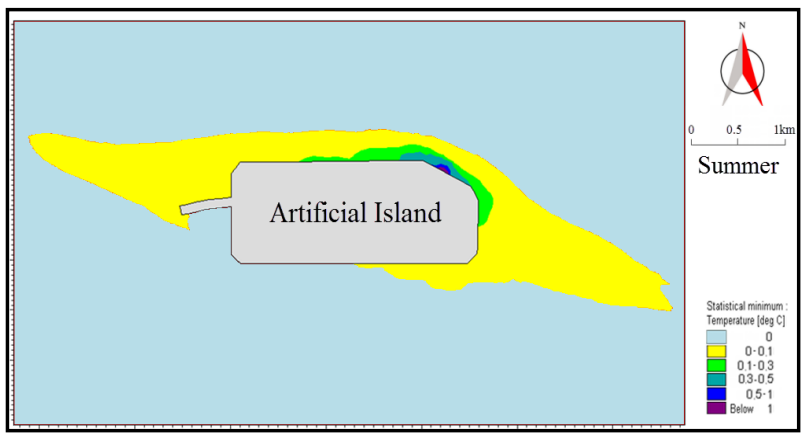

Figure 7. Equivalent envelope line of maximum temperature drop near drains in summer. 


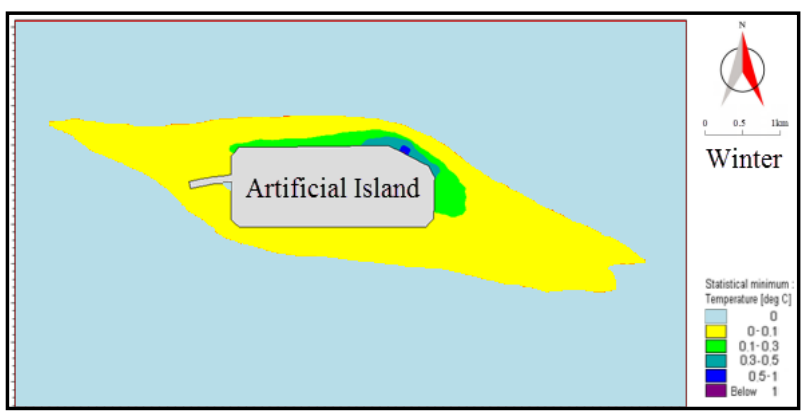

Figure 8. Equivalent envelope line of maximum temperature drop near drains in winter.

Table 2. Spatial distribution statistical parameters of water temperature drop near drains in summer.

\begin{tabular}{ccccc}
\hline \multirow{2}{*}{ Term } & \multicolumn{4}{c}{ Temperature drop } \\
\cline { 2 - 5 } & $\Delta \mathrm{T} \geq 1^{\circ} \mathrm{C}$ & $\Delta \mathrm{T} \geq 0.5^{\circ} \mathrm{C}$ & $\Delta \mathrm{T} \geq 0.3^{\circ} \mathrm{C}$ & $\Delta \mathrm{T} \geq 0.1^{\circ} \mathrm{C}$ \\
\hline Length (m) & 230 & 1150 & 2300 & 6900 \\
Width (m) & 100 & 220 & 260 & 1400 \\
Area $\left(\mathrm{km}^{2}\right)$ & 0.023 & 0.241 & 0.575 & 6.68 \\
\hline
\end{tabular}

Table 3. Spatial distribution statistical parameters of water temperature drop near drains in winter.

\begin{tabular}{ccccc}
\hline \multirow{2}{*}{ Term } & \multicolumn{4}{c}{ Temperature drop } \\
\cline { 2 - 5 } & $\Delta \mathrm{T} \geq 1^{\circ} \mathrm{C}$ & $\Delta \mathrm{T} \geq 0.5^{\circ} \mathrm{C}$ & $\Delta \mathrm{T} \geq 0.3^{\circ} \mathrm{C}$ & $\Delta \mathrm{T} \geq 0.1^{\circ} \mathrm{C}$ \\
\hline Length (m) & 220 & 1380 & 3350 & 7400 \\
Width (m) & 130 & 240 & 450 & 1850 \\
Area $\left(\mathrm{km}^{2}\right)$ & 0.027 & 0.312 & 0.928 & 9.73 \\
\hline
\end{tabular}

\section{The Effect of Low Temperature Drainage on Environment}

Based on the predicted results, the low temperature water formed an extension of the strip area around the drain under the action of tide current. And due to the local influence of artificial island, the pollutant zone extended along the direction of the shore boundary attaching to the bank near the drain. In the summer hydrological conditions, the velocity of tide current field is larger, and the diffusion condition is better, so the influence range of the low temperature water is larger than winter, but large temperature drop covered by a smaller area. The typical pollution load values are represented by the size of the pollution belt as follows:

1) In summer, the pollution zone near the drains that the maximum temperature drop greater than $1^{\circ} \mathrm{C}$ was approximated to a band range of the length of $230 \mathrm{~m}$, width of $100 \mathrm{~m}$, and the area of the $0.023 \mathrm{~km}^{2}$; and the zone that greater than $0.1^{\circ} \mathrm{C}$ was approximated to the length of $6900 \mathrm{~m}$, width of $1400 \mathrm{~m}$, and the area of $6.68 \mathrm{~km}^{2}$. 
2) In winter, the pollution zone near the drains that the maximum temperature drop greater than $1^{\circ} \mathrm{C}$ was approximated to a band range of the length of $220 \mathrm{~m}$, width of $130 \mathrm{~m}$, and the area of the $0.027 \mathrm{~km}^{2}$; and the zone that greater than $0.1^{\circ} \mathrm{C}$ was approximated to the length of $7400 \mathrm{~m}$, width of $1850 \mathrm{~m}$, and the area of $9.73 \mathrm{~km}^{2}$.

In summary, the influence range of low temperature drainage was small, and pollution near the drain was more serious. In a full tide current, the average value of the pollution load in the water was much lower than the maximum value, because the equivalent line was selected as the maximum value at different time, which appeared only in an instant.

In addition, according to Pollution control standards for marine sewage disposal project (in China) and Seawater quality standard, the range allowed by the sea area is $3.0 \mathrm{~km}^{2}$, and the water temperature change cannot exceed $4^{\circ} \mathrm{C}$. So it can be concluded that the low temperature drainage of LNG project has a less impact on the water environment in the research sea area.

\section{Conclusion and Prospect}

\subsection{Conclusion}

1) Simulation results show that, the low temperature water formed an extension of the strip area around the drain under the action of tide current. And due to the local influence of artificial island, the pollutant zone extended along the direction of the shore boundary attaching to the bank near the drain. In the summer hydrological conditions, the velocity of tide current field is larger, and the diffusion condition is better, so the influence range of the low temperature water is larger than winter, but large temperature drop covered by a smaller area.

2) In summer, the pollution zone near the drains that the maximum temperature drop greater than $1^{\circ} \mathrm{C}$ was approximated to a band range of the length of $230 \mathrm{~m}$, width of $100 \mathrm{~m}$, and the area of the $0.023 \mathrm{~km}^{2}$. In winter, the zone was approximated to a band range of the length of $220 \mathrm{~m}$, width of $130 \mathrm{~m}$, and the area of the $0.027 \mathrm{~km}^{2}$.

3) The predicted result was the maximum increment of pollutant concentration in adverse hydrological condition, that is, the concentration of pollutant was selected as the maximum concentration at different time in the whole simulation period. This maximum occurs only in an instant. Therefore, in a full tide current, the average value of the pollution load in the water was much lower than the maximum value. The simulation results also show that the maximum increment of the pollutant concentration in the project area was also relatively small, therefore the low temperature drainage of the project was relatively small impact on the ocean environment nearby.

\subsection{Prospect}

1) This paper was based on the numerical simulation of 2-D model. Actual water flow has three dimensional characteristics, so 3-D model is more appro- 
priate to reflect the actual flow of water. The future research may consider using the 3-D model to simulate the sea water transport characteristics and pollutants.

2) The influence of residual current and wave was not considered in this paper, so the simulation of the water flow couldn't show the nonlinear characteristics of the actual coastal water. These factors should be considered in further research in the future.

3) The heat exchange mechanism between the low temperature water discharge and the natural water body is different from that of warm water discharge, and this paper has not carried out in-depth research. These factors can be considered in further research in the future in order to better simulate imitate the transport characteristics of temperature field after the cold water enters the natural water body.

\section{Acknowledgements}

Work partially supported by grant of the special funds from Ocean and Fisheries Bureau of Jiangsu Province (key technical research on the discharge of sewage in deep sea area).

\section{References}

[1] Wang, H.B. (2009) Research in Development and Application of China's LNG Industry. Daqing Petroleum Institute.

[2] Dong, Y.H. (1997) Two-Dimensional Numerical Simulation of Temperature or Concentration Field in River Channels. Journal of Yangtze River Scientific Research Institute.

[3] Luo, B. and Zhu, J.X. (1999) Application of Finite Node Method to Hot Water Discharge in Power Plant. Electric Power Survey, 1999(01).

[4] Li, Z.H. and Zhu, Q.M. (2013) Numerical Simulation on Cooling Water Project over an Artificial Land Engineering. Electric Power Technology and Environmental Protection, 2003, 19(3).

[5] Wu, H.J., Wang, Z.G. and Chen, S.F. (2005) Numerical Simulation of Cooling Water Dispersion for Coastal Power Station. Electric Power Technology and Environmental Protection, 2005(4).

[6] Zhang, X.Q. and Sun, Y.L. (2005) Numerical Simulation of 3D Tidal Current in the Offshore Area of Jiaonan. Periodical of Ocean University of China, No. 4, 579-582.

[7] Wang, X.C., Sun, C.Q., Sun, Y.L., et al. (2000) Study on Impact of Jiaozhou Bay SeaFilling on Hydrodynamic Environment. Marine Environmental Science, No. 3, 55 59. 
Submit or recommend next manuscript to SCIRP and we will provide best service for you:

Accepting pre-submission inquiries through Email, Facebook, LinkedIn, Twitter, etc. A wide selection of journals (inclusive of 9 subjects, more than 200 journals)

Providing 24-hour high-quality service

User-friendly online submission system

Fair and swift peer-review system

Efficient typesetting and proofreading procedure

Display of the result of downloads and visits, as well as the number of cited articles Maximum dissemination of your research work

Submit your manuscript at: http://papersubmission.scirp.org/

Or contact wjet@scirp.org 